\title{
Deposition of carbenicillin aerosols in cystic fibrosis: effects of nebuliser system and breathing pattern
}

\author{
S P NEWMAN, G WOODMAN, S W CLARKE \\ From the Department of Thoracic Medicine, Royal Free Hospital and School of Medicine, London
}

\begin{abstract}
Antibiotic aerosol treatment is successful in treating Pseudomonas infection in somet patients with cystic fibrosis, but the amount of drug reaching the lungs is unknown. The deposition patterns of carbenicillin aerosols delivered from two commercially available nebuliser systems (the $e_{\infty}^{\omega}$ Turret nebuliser plus Maxi compressor and the Inspiron nebuliser plus Traveller compressor) haveo been compared in six patients with cystic fibrosis during tidal breathing. The aerosol mass median diameters were $3 \cdot 2$ and $7 \cdot 3 \mu \mathrm{m}$. In addition, the aerosol from the Turret-Maxi nebuliser system was inhaled by a combination of tidal and deep breathing. After two minutes' breathing via a mouthpiece the mean (SEM) deposition in the lungs was $15.60(1.5) \mathrm{mg}$ carbenicillin with the Turret nebuliser pluse Maxi compressor, but only 6.54 (1.09) $\mathrm{mg}$ with the Inspiron nebuliser plus Traveller compressor; the0. distribution pattern within the lung was significantly more peripheral with the former nebuliserס system. These differences may be ascribed partly to the smaller droplet size from the Turret systems and partly to the higher nebulisation rate from the more powerful Maxi compressor. Tidal plus deepo breathing produced a further small but non-significant increase in lung aerosol deposition. A seventhő patient, who failed to complete the trial, had little aerosol deposited in his lungs because he inhaled $\mathbb{Q}$ through his nose. These results emphasise the importance of correct selection of nebuliser equipment $\overrightarrow{\overrightarrow{0}}$ for antibiotic aerosol treatment.
\end{abstract}

Antibiotic aerosol treatment originated in the 1940s, when various antibiotics were inhaled either as nebulised solutions ${ }^{12}$ or as dry powders ${ }^{3}$ to treat respiratory tract infections. Although this practice waned in popularity, it has recently been revived, particularly to treat Pseudomonas infection in some patients with cystic fibrosis. ${ }^{4-7}$ The efficacy of aerosol antibiotic treatment may depend in part on the choice of nebuliser equipment; in vitro laboratory studies have suggested that the quantities of gentamicin, ${ }^{8}$ carbenicillin, ${ }^{9}$ ceftazidime, and colistin ${ }^{10}$ reaching the lungs may vary widely according to the type of nebuliser and compressor.

Relatively little is known about the site of deposition of antibiotic aerosol within the respiratory tract, and the extent to which the aerosol penetrates to the more peripheral lung regions. In this study in patients with cystic fibrosis we have used radiotracer techniques to assess the deposition patterns of antibiotic aerosols delivered from two commercially available

Address for reprint requests: Dr S P Newman, Department of Thoracic Medicine, Royal Free Hospital, London NW3 2QG.

Accepted II January 1988 nebuliser systems with widely differing droplet size distributions. We have also compared the deposition following tidal breathing with the deposition following a combination of tidal and deep breaths.

\section{Methods}

Radioaerosol studies were performed on seven patients with cystic fibrosis (five men, two women, age range 22-48 years) selected from outpatient clinics at the Brompton Hospital, London. All were being o treated with antibiotics by aerosol on a regular basis. $N$ Forced expiratory volume in one second $\left(\mathrm{FEV}_{1}\right)$ స్ట ranged from $16 \%$ to $57 \%$ of the predicted value. "O Informed consent in writing was obtained from each 0

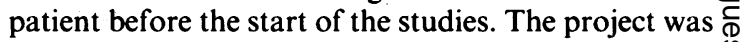
passed by the ethical practices subcommittees of both $\stackrel{\oplus}{+}$ the Royal Free and the Brompton Hospitals and by 0 the Administration of Radioactive Substances Advisory Committee.

Radioactive carbenicillin aerosols were prepared by $\underset{\mathbb{Q}}{\mathbb{Q}}$ adding to $1 \mathrm{~g}$ carbenicillin powder (Pyopen, Bee- $\overline{0}$ chams) $4 \mathrm{ml}$ diethylenetriaminepenta-acetic acid (DTPA) solution labelled with $185 \mathrm{MBq}(5 \mathrm{mCi})$ 응 
technetium-99m. Aerosols generated from this mixture contain drug and radiolabel, so that the distribution of radiolabel in the respiratory tract reflects that of the drug. ${ }^{12-14}$

Aerosols were generated by two combinations of nebuliser and compressor. A Turret nebuliser (MedicAid Ltd, Pagham) coupled to a Maxi Mark 1 compressor (Medix Ltd, Calthorpe) was used to generate an aerosol with a mass median diameter $3 \cdot 2(0 \cdot 2) \mu \mathrm{m}$ (mean (SEM), $\mathrm{n}=8)$ in which $71 \cdot 2 \%(2 \cdot 1 \%)$ of the aerosol mass was contained in droplets under $5 \mu \mathrm{m}$ diameter. By contrast, an Inspiron Mini-neb nebuliser (Bard International Ltd, Sunderland) coupled. to a Traveller compressor (Medix Ltd) was used to make an aerosol with an MMD of $7 \cdot 3(0.3) \mu \mathrm{m}(\mathrm{n}=8)$ in which only $29.0 \%(2.5 \%)$ of the aerosol mass was contained in droplets under $5 \mu \mathrm{m}$ diameter. Droplet sizes, measured by a Malvern Instruments 2600HSD laser particle and droplet analyser, ${ }^{15}$ were similar to those obtained when carbenicillin is diluted with sterile water for injection according to usual clinical practice. ${ }^{9}$ The flow rates generated by the Maxi and Traveller compressors through their respective nebulisers were 9 and $6 \mathrm{l} / \mathrm{min}$. The Inspiron nebuliser was connected to a one way valve system (Ambu-Valve, Tricomed, London), the outlet from which led to a low resistance filter (Inspiron 002290) so that no aerosol was vented into the room; the Turret nebuliser incorporated a built in valve system. Each patient used a different nebuliser to prevent cross contamination and nebulisers, valves, and tubing were sterilised after each experiment.

Radioaerosol studies were performed on three separate days in a randomised order as follows: (1) Inspiron nebuliser plus Traveller compressor with tidal breathing (7.3 $\mu \mathrm{m}$ aerosol); (2) Turret nebuliser plus Maxi compressor with tidal breathing (3.2 $\mu \mathrm{m}$ aerosol; (3) Turret nebuliser plus Maxi compressor with a combination of tidal and deep breathing (3.2 $\mu \mathrm{m}$ aerosol). In the third study patients were instructed to take alternately four tidal breaths and four deep breaths of $1 \cdot 0-1 \cdot 51$ in volume. Inhaled volume, breathing frequency, and minute ventilation were determined by respiratory inductive plethysmography (Respitrace Corporation, Ardsley, New York) which was used to monitor the inhalation manoeuvres as described. ${ }^{16}$ To provide a rough check on the inhaled volume while aerosol was being inhaled, the air inlet to the nebuliser was connected to a Voldyne incentive spirometer (Cheeseborough Ponds Inc, Greenwich, Conneticut). Patients inhaled aerosol for two minutes via a mouthpiece with the body of the nebuliser shielded by a lead screen. Inhalations were preceded by 10 minutes' chest physiotherapy (forced expiration technique ${ }^{17}$ ) to clear loose secretions from the lungs. Forced expiratory volume in one second $\left(\mathrm{FEV}_{1}\right)$ was assessed immediately before aerosol inhalation by spirometry (Vitalograph), and maximum expiratory flow rate at $75 \%$ of the forced vital capacity $\left(\dot{V}_{\max }{ }_{25}\right)$ from an Ohio spirometer coupled to an $x-y$ plotter.

A posterior-anterior scan of radioaerosol in the chest and stomach was performed with a General Electric 400T large field of view gamma camera, starting within 60 seconds of the end of nebulisation. Counting times were 100-200 seconds and at least 40000 counts were collected. Aerosol located in the oropharynx was then determined from a right lateral view of the head. The gamma camera was connected on line to a Nodecrest V77 600 computer, which was used to define "regions of interest" on the scans around the lungs, stomach, and oropharynx. The chest count was corrected for the patient's chest thickness according to the attenuation equations of Fleming. ${ }^{18}$ Counts emanating from the stomach during scans were assumed to have arisen from aerosol initially deposited in the oropharynx and subsequently swallowed. The total amount of carbenicillin initially deposited in the lungs and oropharynx was determined by comparing the counts obtained with those from a lung "phantom" similar in design to the models described previously. ${ }^{1920}$ The phantom consisted of a $25 \mathrm{~cm}$ diameter hollow perspex disc $3 \mathrm{~cm}$ thick, filled with a known amount of the "labelled" carbenicillin (about $5 \mathrm{mg}$ ). The perspex disc was mounted in a wooden frame and positioned $10 \mathrm{~cm}$ from a $1 \mathrm{~cm}$ thick slab of tissue equivalent material to simulate the chest wall. The $10 \mathrm{~cm}$ air gap represented air in the lungs and the perspex disc activity in mid thorax. For scanning the phantom was placed in front of the gamma camera with the tissue equivalent slab in contact with the surface of the collimator.

Each patient had a krypton- $81 \mathrm{~m}$ ventilation scan, after one of the radioaerosol studies, inhaling the radioactive gas from a generator (the Medical Research Council cyclotron). The $20 \%$ contour of the ${ }^{81 \mathrm{~m}} \mathrm{Kr}$ scan was then superimposed on the aerosol images and used to define the lung edge. Radioaerosol counts in three further lung zones (central, : intermediate, and peripheral-fig 1) were determined from three "regions of interest" as described by Agnew et $a l .^{21}$ An aerosol penetration index was defined as the ratio of peripheral zone counts to central zone counts, averaged for the two lungs.

The data were not assumed to be normally distributed. Statistical significance was assessed by the Wilcoxon rank sum test for paired data. ${ }^{22}$

\section{Results}

EFFECT OF NEBULISER SYSTEM

One patient failed to complete the trial for personal 
LEFT LUNG

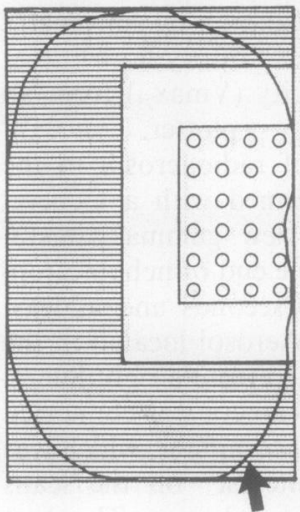

$20 \% \mathrm{Kr} 81 \mathrm{~m}$ contour
RIGHT LUNG

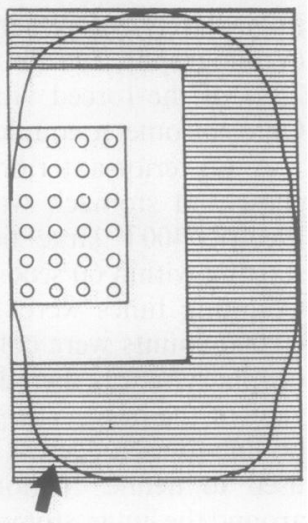

Fig 1 Aerosol distribution within the lungs. The 20\% contour of the krypton-81m ventilation scan is superimposed on the aerosol image and a $5 \times 8$ matrix is fitted to this contour for each lung. Peripheral (cross hatched), intermediate, and central (stippled) regions are defined as shown.

reasons. The mean (SEM) amount of carbenicillin reaching the lungs in the other six patients was 6.54 (1.09) $\mathrm{mg}$ with the Inspiron plus Traveller (fig 2). Deposition was significantly greater at $15.60(1.5) \mathrm{mg}$ with the Turret nebuliser plus Maxi compressor $(p<$ $0.05)$. Peripheral zone deposition was less $(2.84(0.44)$ $\mathrm{mg}$ ) with the Inspiron nebuliser plus Traveller compressor than with the Turret nebuliser plus Maxi compressor $(7.92(0.81) \mathrm{mg} ; \mathrm{p}<0.05)$. The aerosol penetration index was increased from $1.38(0 \cdot 16)$ with the Inspiron nebuliser compared with $2.00(0.22)$ with the Turret nebuliser $(p<0.05)$.

There was a trend towards higher oropharyngeal deposition with the Inspiron (9.55(4.08) $\mathrm{mg}$ ) than with the Turret nebuliser $(4.93(1.19) \mathrm{mg})$, but this was not significant.

Typical scans comparing the deposition patterns for the two nebuliser systems are shown in figure 3.

\section{EFFECT OF BREATHING PATTERN}

Alternate tidal and deep breathing of the $3.2 \mu \mathrm{m}$ aerosol from the Turret nebuliser increased lung deposition in five of the six patients who completed the trial, but overall the rise from $15.60(1.50) \mathrm{mg}$ to $19 \cdot 17$ $(2.06) \mathrm{mg}$ was not significant. Similarly, the peripheral zone depositions $(7.92(0.81) \mathrm{mg} v 9.45(1.06) \mathrm{mg})$, aerosol penetration indices $(2.00(0.22) v 1.76(0.08))$, and oropharyngeal deposition $(4.93(1.19) \mathrm{mg} v 5.47$ $(1.71) \mathrm{mg}$ ) did not differ significantly for the two breathing modes.

The patient who withdrew from the study had inhaled only the $3.2 \mu \mathrm{m}$ aerosol by tidal breathing. In this case only $1.84 \mathrm{mg}$ carbenicillin was deposited in the lungs, compared with a mean of $15.6 \mathrm{mg}$ in the remaining six patients. When he returned to the laboratory it was apparent that he drew aerosol into his mouth via the mouthpiece but inhaled through his nose. A repeat study was performed with the patient wearing a noseclip and the mass of carbenicillin in the lungs rose almost threefold to $4.85 \mathrm{mg}$.

LUNG FUNCTION AND INHALATION MANOEUVRES Lung function, inhalation volumes and breathing frequencies were similar on each study day (table 1 ). With alternate tidal and deep breathing, minute $\vec{x}$ ventilation increased compared to tidal breathing alone $(\mathrm{p}<0.05)$.

\section{Discussion}

Deposition of carbenicillin was determined by mixing the ${ }^{99 m} \mathrm{Tc}$ and drug solution within the nebulisers rather $\frac{D}{O}$ than by labelling the drug with the radionuclide chemically. Droplets released subsequently are $\vec{\varphi}$ assumed to contain drug and radiolabel in the same $\infty_{\infty}^{\infty}$ proportions as in the nebuliser reservoir, so that the distribution of radioaerosol in the lungs and oropharynx reflects that of the drug. The validity of this assumption has been discussed by Dashe $e t a l^{12}$ and by Ruffin et $a l,{ }^{13}$ and the technique has been used to $\frac{\varnothing}{\varnothing}$ quantify the deposition of bronchodilators, ${ }^{121323}$ his- $\varrho$ tamine, ${ }^{20}$ and gentamicin. ${ }^{14}$ The radionuclide was $\stackrel{\overrightarrow{0}}{\overrightarrow{0}}$ labelled to DTPA, since the rate of absorption of this substance through the lungs ${ }^{24} 25$ is sufficiently slow for scanning to be completed before there is appreciable

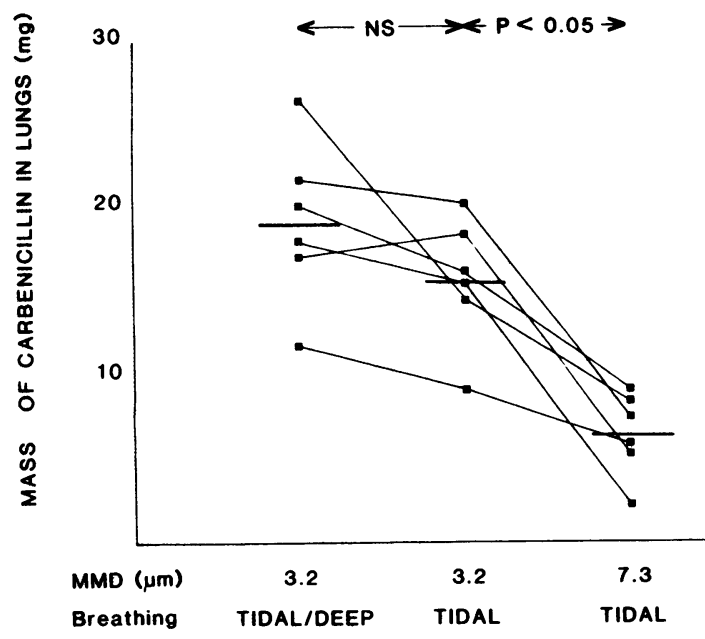

Fig 2 Mass of carbenicillin ( $\mathrm{mg}$ ) deposited in the lungs in six patients for two nebuliser systems-Turret nebuliser plus Maxi compressor (droplet mass median diameter (MMD) $3.2 \mu \mathrm{m}$ ) and Inspiron nebuliser plus Traveller compressor (MMD $7.3 \mu \mathrm{m}$ ) and for two breathing patterns with the Turret-Maxi nebuliser system. 


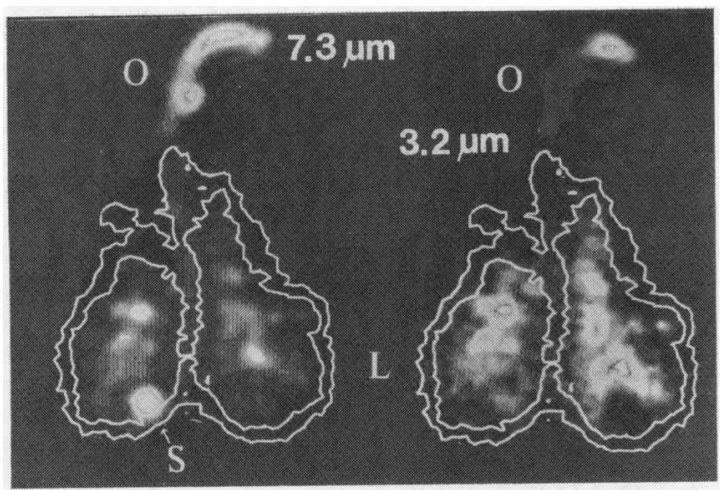

Fig 3 Typical deposition patterns with the Inspiron nebuliser plus Traveller compressor (droplet mass median diameter (MMD) $7 \cdot 3 \mu \mathrm{m}$ ) and the Turret nebuliser plus Maxi compressor (droplet MMD $3 \cdot 2 \mu \mathrm{m}$ ) in one patient with cystic fibrosis. The $10 \%$ and $20 \%$ contours of the krypton$81 m$ ventilation scan are shown. $O$, oropharynx; $L$, lungs; $S$, stomach. The views are posterior-anterior.

loss of tracer from the field of view; inhalation was restricted to two minutes to further minimise the effects of absorption of the radiotracer. The radiation dose to the lungs has been estimated as $200 \mu \mathrm{Gy}(20$ $\mathrm{mrad})$, which is about half that from a chest radiograph. ${ }^{26}$

The deposition data indicate that the amount of antibiotic aerosol delivered to the patient's lungs may be influenced dramatically by choice of nebuliser system, as predicted from in vitro studies. ${ }^{8-10}$ During two minutes' nebulisation more drug was delivered to the patient from the Turret nebuliser with the Maxi compressor $(20.5 \mathrm{mg}$ in lungs plus oropharynx) than from the Inspiron nebuliser plus Traveller compressor ( $16.1 \mathrm{mg})$, presumably because the Turret was driven at a higher compressed gas flow rate. With the Turret nebuliser plus Maxi compressor $76 \%$ of the aerosol reaching the patient was deposited in the lungs, compared with $41 \%$ for the Inspiron nebuliser plus

Details of lung function and inhalation manoeuvres (mean (SEM) values) for the six patients who completed all three studies.

\begin{tabular}{|c|c|c|c|}
\hline Nebuliser system & $T U+M A$ & $T U+M A$ & $I N+T R$ \\
\hline $\begin{array}{l}\text { MMD }(\mu \mathrm{m}) \\
\text { Breathing pattern } \\
\text { FEV }_{1}(\mathrm{l}) \\
\dot{V}_{\max }(1 / \mathrm{s}) \\
\text { Tidal breath }(1) \\
\text { Deep breath (l) } \\
\text { Breaths/minute } \\
\text { Minute ventilation (I) }\end{array}$ & $\begin{array}{c}3.2 \\
\text { Tidal }+ \text { deep } \\
1.37(0 \cdot 13) \\
0.26(0.05) \\
0.77(0.10) \\
1.34(0.15) \\
18.3(2 \cdot 8) \\
18.6(3.4)\end{array}$ & $\begin{array}{l}3.2 \\
\text { Tidal } \\
1.38(0.14) \\
0.28(0.05) \\
0.74(0.08) \\
-\quad \\
18.0(0.9) \\
13.4 \quad(1.7)\end{array}$ & $\begin{array}{l}7.3 \\
\text { Tidal } \\
1.41(0.12) \\
0.30(0.02) \\
0.82(0.05) \\
\frac{19.5}{19}(2 \cdot 7) \\
16.1 \quad(2 \cdot 8)\end{array}$ \\
\hline
\end{tabular}

MMD, mass median diameter; $\operatorname{Vmax}_{25}$, maximum expiratory flow rate at $75 \%$ of the forced vital capacity; TU, Turret nebuliser; IN, Inspiron nebuliser; TR, Traveller compressor; MA, Maxi compressor.
Traveller compressor, the difference presumably being due to the smaller droplet MMD from the Turret nebuliser. Different combinations of nebulisers and compressors produce droplets with widely differing size distributions ${ }^{9}$ and droplets smaller than $5 \mu \mathrm{m}$ diameter are said to constitute the "respirable range." 27 Some nebuliser systems may be ineffective because they are unable to deliver the dose to the required site of action in sufficient quantity. The droplets of smaller size also penetrated better to the peripheral zone of the lungs, which suggests enhanced aerosol delivery to the smaller conducting airways; the required site of deposition of antibiotic aerosols within the bronchial tree is, however, poorly understood. As noted in earlier studies, ${ }^{19242829}$ only a small percentage of the drug dose in a nebuliser actually reaches the lungs. With nebulisation for a fixed time rather than to dryness the difference between the two nebuliser systems was accentuated, and it would be possible to compensate for this by increasing the delivery time with the Inspiron-Traveller system. Nebulisation of a full treatment dose to dryness, however, takes more than 30 minutes for the relatively weak Traveller compressor, ${ }^{9}$ and many patients will be unwilling or unable to comply with treatment of this duration.

The addition of deep breathing to normal tidal breathing for the $3.2 \mu \mathrm{m}$ aerosol caused a small increase in deposition, but the additional respiratory effort required is probably not justified in terms of improved drug delivery. The increased volume inhaled during deep breathing should have carried aerosol to more peripheral lung regions. ${ }^{30}$ Patients maintained the same breathing rate, however, while taking deep breaths, indicating that these were inhaled relatively rapidly. This would tend to deposit aerosol centrally, ${ }^{30}$ thus countering the effect of inhaling deeply, and this may explain the similar aerosol distributions for the two breathing modes. Attention to inhalation technique may be important, however. The low deposition in the patient who inhaled through the nose while receiving the aerosol via a mouthpiece suggests that some patients may be using their nebulisers incorrectly and may consequently derive little therapeutic benefit. The use of a noseclip or facemask should help to eliminate simple errors of this type, and could usefully be considered in patients who are not deriving the expected benefit from treatment.

The nebuliser systems tested in this study may have represented opposite extremes so far as droplet mass median diameters are concerned; most other systems probably have an MMD in the range 3-7 $\mu \mathrm{m} .{ }^{9}$ Large droplet sizes are sometimes, but not always, associated with relatively weak "portable" brands of compressor. Droplet MMD varies inversely with the pressure or flow rate generated by a compressor, but it also depends on the type of nebuliser. In vitro studies have 
shown that the weaker compressors are often unsatisfactory because of the time taken to nebulise a standard dose of carbenicillin ${ }^{9}$; this study indicates that weaker compressors may also be unsatisfactory because they lead to the generation of larger aerosol droplets, fewer of which reach the lungs. A relatively powerful compressor, coupled to a nebuliser with a droplet MMD of less than $5 \mu \mathrm{m}$, is thus the system of choice for antibiotic aerosol treatment.

These studies have been supported by a grant from the Cystic Fibrosis Research Trust. We are grateful to Dr M E Hodson, Sir John Batten, Dr M J Smith, and Dr R J Stead for the selection of patients.

\section{References}

1 Southwell N. Inhaled penicillin in bronchial infections. Lancet 1946;ii:225-7.

2 Mutch N. Inhalation of chemotherapeutic substances. Lancet 1944;ii:776-80.

3 Taplin GV, Cohen SH, Mahoney EB. Prevention of postoperative pulmonary infections. JAMA 1948;138:4-8.

4 Hodson ME, Penketh ARL, Batten JC. Aerosol carbenicillin and gentamicin treatment of pseudomonas aeruginosa infection in patients with cystic fibrosis. Lancet 1981;ii:1137-9.

5 Wall MA, Terry AB, Eisenberg J, McNamara M. Inhaled antibiotics in cystic fibrosis. Lancet 1983;i:1325.

6 Stead RJ, Hodson ME, Batten JC. Nebulised ceftazidime compared with gentamicin and carbenicillin in adults with cystic fibrosis [Abstract]. Thorax 1985;40:704.

7 Littlewood JM, Miller MG, Ghoneim AT, Ramsden CH. Nebulised colomycin for early pseudomonas colonisation in cystic fibrosis. Lancet 1985; i:865.

8 Newman SP, Pellow PGD, Clay MM, Clarke SW. Evaluation of jet nebulisers for use with gentamicin solution. Thorax 1985;40:671-6.

9 Newman SP, Pellow PGD, Clarke SW. Choice of nebulisers and compressors for delivery of carbenicillin aerosol. Eur J Respir Dis 1986;69:160-8.

10 Newman SP, Pellow PGD, Clarke SW. Efficient nebulisation of powdered antibiotics. Int J Pharm 1987;36: 55-60.

11 Cotes JE. Lung function: assessment and application in medicine. Oxford: Blackwell Scientific Publications, 1979.

12 Dashe CK, Ponto RA, Ganapes $\mathrm{CH}$, Drage CW, Kronenberg RS. The distribution of nebulised isoproterenol and its effect on regional ventilation and perfusion. Am Rev Respir Dis 1974;110:293-300.

13 Ruffin RE, Kenworthy MC, Newhouse MT. Response of asthmatic patients to fenoterol inhalation: a method of quantifying the airway bronchodilator dose. Clin Pharmacol Ther 1978;23:338-45.
14 Ilowite JS, Gorvoy JD, Scarpelli EM, Smaldone GC Regional and whole lung deposition of aerosolised? gentamicin in patients with cystic fibrosis: relation to sputum levels [Abstract]. Am Rev Respir Dis. 1986;133:A246.

15 Newman SP, Pellow PGD, Clarke SW. Droplet sized distributions of nebulised aerosols for inhalation therapy. Clin Phys Physiol Meas 1986;7:139-46.

16 Newman SP, Woodman G, Clarke SW, Sackner MA $\overrightarrow{0}$ Effect of InspirEase on the deposition of metered doseaerosols in the human respiratory tract. Chest $\vec{\omega}$ 1986;89:551-6.

17 Pryor JA, Webber BA, Hodson ME, Batten JC. Evalua tion of the forced expiration technique as an adjunct to postural drainage in the treatment of cystic fibrosis. $B r$ Med J 1979;ii:417-8.

18 Fleming JS. A technique for absolute measurement of $\stackrel{\omega}{\infty}$ activity using a gamma camera and computer. Physo Med Biol 1979;24:176-80.

19 Asmundsson T, Johnson RF, Kilburn KH, Goodrich JK Efficiency of nebulisers for depositing saline in theo human lung. Am Rev Respir Dis 1973;108:506-12.

20 Ruffin RE, Dolovich MB, Wolff RK, Newhouse MT. The $\overrightarrow{0}$ effects of prefential deposition of histamine in the $\infty_{\infty}^{\infty}$ human airway. Am Rev Respir Dis 1978;117:485-92.

21 Agnew JE, Bateman JRM, Pavia D, Clarke SW. Radio-o nuclide demonstration of ventilatory abnormalities in mild asthma. Clin Sci 1984;66:525-31.

22 Siegel S. Non-parametric statistics for the behaviouraf sciences. Tokyo: McGraw-Hill Kogakusha, 1956.

23 Ruffin RE, Dolovich MB, Oldenberg FA, Newhouse MT. The preferential deposition of inhaledO isoproterenol and propranolol in asthmatic patients. Chest 1981;80(suppl):904-7.

24 Chopra SK, Taplin GV, Tashkin DP, Elam D. Lung? clearance of soluble radioaerosols of different molecular weights in systemic sclerosis. Thorax 1979;34:63-7.

25 Elwood RK, Kennedy S, Belzberg A, Hogg JC, Pare PD. Respiratory mucosal permeability in asthma. $A m \operatorname{Re} \underline{\text { S }}$. Respir Dis 1983;128:523-7.

26 Advisory Committee on Biological Effects of Ionising Radiation. Consideration of the health benefit-costo analysis for activities involving ionising radiation? exposures and alternatives. Washington DC: US $\frac{7}{0}$ Environmental Protection Agency, 1977.

27 Newman SP, Clarke SW. Therapeutic aerosols: 1- N Physical and practical aspects [Editorial]. Thorax 1983;38:881-6.

28 Alderson PO, Secker-Walker RH, Strominger DB, N Markham J, Hill RL. Pulmonary deposition of aerosols in children with cystic fibrosis. $J$ Pediatr 1974;84:479-84.

29 Lewis RA, Fleming JS. Fractional deposition from a jet@ nebuliser: how it differs from a metered dose inhaler. $\mathrm{Br}^{-}$ J Dis Chest 1985;79:361-7.

30 Pavia D, Thomson ML, Clarke SW, Shannon HS. Effect $\frac{\bar{D}}{\mathbb{D}}$ of lung function and mode of inhalation on penetration of aerosol into the human lung. Thorax 1977;32:194-7. 